\title{
c-Myc promotes differentiation of human epidermal stem cells
}

\author{
Alberto Gandarillas and Fiona M. Watt ${ }^{\mathbf{1}}$ \\ Keratinocyte Laboratory, Imperial Cancer Research Fund (ICRF), London, WC2A 3PX, UK
}

The epidermis contains two types of proliferative keratinocyte: stem cells, with unlimited self-renewal capacity, and transit amplifying cells, those daughters of stem cells that are destined to withdraw from the cell cycle and terminally differentiate after a few rounds of division. In a search for factors that regulate exit from the stem cell compartment, we constitutively expressed c-Myc in primary human keratinocytes by use of wild-type and steroid-activatable constructs. In contrast to its role in other cell types, activation of c-Myc in keratinocytes caused a progressive reduction in growth rate, without inducing apoptosis, and a marked stimulation of terminal differentiation. Keratinocytes can be enriched for stem or transit amplifying cells on the basis of $\beta_{1}$ integin expression and by use of this method to fractionate cells prior to c-Myc activation, we found that c-Myc acted selectively on stem cells, driving them into the transit amplifying compartment. As a result, activation of c-Myc in epidermis reconstituted on a dermal equivalent led to premature execution of the differentiation program. The transcriptional regulatory domain of c-Myc was required for these effects because a deletion within that domain acted as a dominant-negative mutation. Our results reveal a novel biological role for c-Myc and provide new insights into the mechanism regulating epidermal stem cell fate.

[Key Words: Involucrin; integrins; epidermis; keratinocytes; 4-hydroxytamoxifen]

Received June 6, 1997; revised version accepted August 27, 1997.

The epidermis is a tissue in which proliferation and terminal differentiation are compartmentalized and tightly regulated. Throughout adult life, proliferation continues in the basal layer of the epidermis and keratinocytes undergo terminal differentiation as they move through the suprabasal layers to the tissue surface (for review, see Watt 1989). The balance between proliferation and differentiation is such that, for every new cell that is produced in the basal layer, a terminally differentiated cell is shed from the surface of the epidermis. The proliferative compartment contains at least two types of keratinocyte: stem cells, which have an unlimited capacity for self-renewal, and transit amplifying cells, which are destined to withdraw from the cell cycle and differentiate after a few rounds of division (Potten and Morris 1988; Hall and Watt 1989). Although the process of terminal differentiation has been studied extensively (Fuchs and Bryne 1994), nothing is known about the events that regulate the transition from the stem cell to the transit amplifying cell compartment. Until recently, there were no biochemical markers to distinguish stem and transit amplifying cells, but it is now known that stem cells express twofold higher surface levels of $\beta_{1}$ integrins than transit amplifying cells (Jones and Watt 1993; Jones et al. 1995).

c-M yc belongs to the basic helix-loop-helix/leucine-

${ }^{1}$ Corresponding author.

E-MAIL watt@icrf.icnet.uk; FAX 44-171-269-3078. zipper family of DNA-binding proteins and regulates transcription through interactions with Max, another family member (for review, see Amati and Land 1994). Overexpression of c-Myc induces proliferation and neoplastic transformation in many types of cells (for review, see Cooper 1990; DePinho et al. 1991; M orgenbesser and DePinho 1994) and induces apoptosis, particularly when nontransformed cells are deprived of growth factors (Askew et al. 1991; Evan et al. 1992; for review, see Packham and Cleveland 1995). Down-regulation of c-M yc accompanies differentiation of a range of cell types and ectopic expression of $\mathrm{c}-\mathrm{M}$ yc has been shown to inhibit differentiation in a variety of in vitro models (DePinho et al. 1991; Henriksson and Lüscher 1996).

We and others have shown that the level of c-M yc mRNA decreases when keratinocytes undergo terminal differentiation (Younus and Gilchrest 1992; Yaar et al. 1993; Gandarillas and Watt 1995; Hurlin et al. 1995b). $\mathrm{TGF} \beta_{1}$ is thought to inhibit keratinocyte proliferation by downregulating C-M yc (Pietenpol et al. 1990; Alexandrow et al. 1995) and c-M yc antisense inhibits keratinocyte growth (Hashiro et al. 1991). These and other observations have led to the suggestion that in keratinocytes, as in other cell types, the function of c-M yc is to promote proliferation and that c-M yc downregulation is a prerequisite for the initiation of terminal differentiation (Chin et al. 1995; Hurlin et al. 1995 a,b). To test this idea, we have studied the consequences of infecting normal human epidermal keratinocytes with retroviral vectors ex- 
pressing c-Myc. Our data show that, contrary to expectations, c-M yc does not stimulate proliferation or apoptosis, but stimulates terminal differentiation by driving entry of stem cell progeny into the transit amplifying cell compartment.

\section{Results}

\section{Expression of c-Myc constructs}

Transfection of normal human epidermal keratinocytes is very inefficient, and for this reason, we used retroviral infection to overexpress c-Myc. We infected keratinocytes with the empty retroviral vector, pBabe puro, which confers puromycin resistance and serves as a control, and also with pBabe puro containing wild type cMyc under the control of the retroviral $5^{\prime}$ long terminal repeat (LTR). To monitor the kinetics of action of c-M yc, we also used two steroid-activatable constructs, c-MycER and D106-143c-M ycER (Littlewood et al. 1995).

C-M ycER is a fusion protein in which the ligand-binding domain (ER) of a mutant estrogen receptor, G525R (Danielian et al. 1993), is fused to the carboxyl terminus of c-M yc. ER lacks intrinsic transactivation activity; it responds to the synthetic steroid 4-hydroxytamoxifen $(\mathrm{OHT})$, but not to estrogen, thus obviating the need to use phenol red-free culture medium and to strip steroid hormones from fetal calf serum (Littlewood et al. 1995). In this construct, c-M ycER protein is constitutively expressed, but is inactive unless OHT is supplied. On addition of OHT, c-M ycER induces proliferation and apoptosis in the same manner as wild-type c-M yc (Littlewood et al. 1995; Alarcon et al. 1996). The 106-143 deletion of c-Myc lies in the transactivation domain. Although the deleted sequence is not essential for transactivation, it is required for suppression of transcription (Li et al. 1994; Lee et al. 1996) and for c-M yc activity in transformation, proliferation, apoptosis, and differentiation assays; in these assays the mutation acts as a dominant negative (Dang et al. 1989; Sawyers et al. 1992; Littlewood et al. 1995; C añelles et al. 1997).

In the experiments to be described, KpBabe refers to keratinocytes expressing the empty vector, Kmyc to cells expressing wild-type c-M yc, and KmycER and K106ER to cells expressing the steroid-inducible constructs. MycER and 106ER refer to the protein products of c-M ycER and D106-143c-M ycER, respectively. Keratinocytes were infected with the retroviral vectors, selected in puromycin in the absence of OHT, and then frozen down or passaged for experimental analysis.

Keratinocytes expressing the different retroviral vectors were extracted and immunoblotted with an antibody to c-M yc (Fig. 1A). In KpBabe, a faint band of $\sim 60$ $k D$, together with several lower molecular weight bands, was detected in the presence or absence of OHT. The intensity of the 60-kD band was increased in Kmyc cells. In KmycER a major band of about 99 kD was present, whereas in K106ER there was a band of $97 \mathrm{kD}$, consistent with the reported molecular weights of MycER and 106ER (Littlewood et al. 1995). In KmycER there was a second band of $87 \mathrm{kD}$ as also observed when MycER is expressed in fibroblasts (T. Littlewood, pers. comm.).

The apparent molecular weights of the major MycER and $\mathrm{C}-\mathrm{M}$ yc bands are consistent with that reported for c-M yc-2 (64 kD), which is translated from the canonical AUG codon and functions to induce proliferation and transformation in a variety of cell types (Blackwood et al. 1994; Hann et al. 1994; Spotts et al. 1997). The smaller bands might reflect partial proteolysis or post-translational modification of $\mathrm{c}-\mathrm{M} \mathrm{yc}$, or could correspond to the
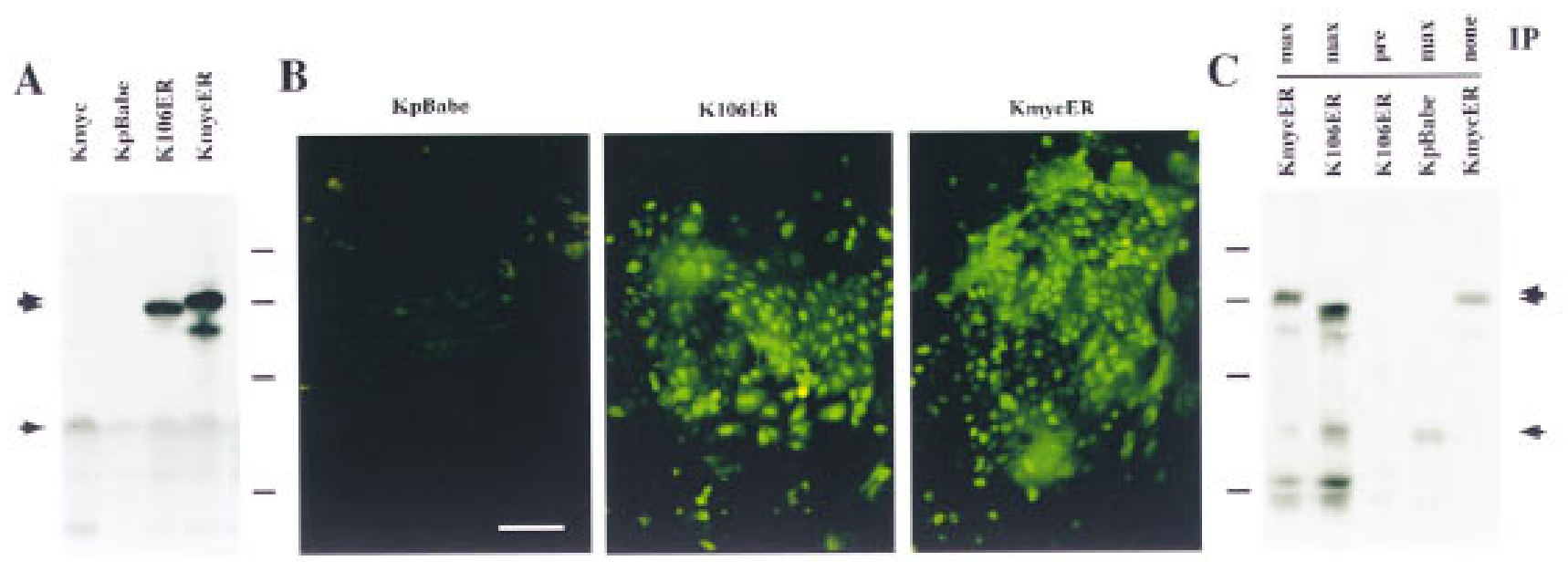

Figure 1. Expression of c-Myc constructs and MycER/M ax complex formation. (A) Western blot probed with anti-c-Myc antibody, 9E10. Cells were cultured in the absence of OHT. (Double-headed arrow) Position of 106ER (bottom) and major M ycER (top) protein bands. (Single-headed arrow) Position of major wild-type c-Myc band. (B) Immunofluorescence staining of keratinocyte colonies maintained in the absence of OHT. Bar, $500 \mu \mathrm{m}$. (C) Keratinocytes were treated with OHT for $24 \mathrm{hr}$. Immunoprecipitation was performed with an anti-Max antibody $(\mathrm{Mx}$ ) or preimmune serum (pre) and immunoblotted with anti-c-Myc (9E10). As a positive control, cell extracts were immunoblotted without prior immunopreci pitation (none). Arrows are as in A. Positions of molecular mass markers $(200,97.4,69,46$ kD) are indicated by short horizontal lines in A and C. 
recently identified Myc-S proteins (Spotts et al. 1997); however, because Myc-S proteins are expressed in proliferative and neoplastic cells, they are unlikely to interfere with the known biological activities of c-Myc (Spotts et al. 1997).

We examined the abundance and cellular distribution of c-M yc by immunofluorescence microscopy of infected clones of keratinocytes (Fig. 1B and data not shown). The intensity of nuclear staining was greatly increased in keratinocytes expressing $\mathrm{c}-\mathrm{M}$ yc, $\mathrm{M}$ ycER, and 106ER compared with those expressing the empty vector. c-Myc, MycER, and 106ER localized to the nucleus in the presence or absence of OHT. Confocal analysis and double labeling for C-M yc and involucrin, a differentiation marker, established that differentiating suprabasal cells continued to express MycER (data not shown).

By use of a combination of immunoprecipitation and Western blotting, we showed that the M ycER and 106ER proteins were able to bind to endogenous Max (Fig. 1C). The dominant-negative activity of 106ER is thus likely to be caused by competition with endogenous c-M yc for Max binding, as proposed previously (Dang et al. 1989; Sawyers et al. 1992; Cañelles et al. 1997).

Northern blot analysis of members of the Myc network

We examined $M$ yc levels by Northern blotting of total RNA from KpBabe, K106ER, and KmycER, grown in the absence of OHT or treated with OHT for 2 or 9 days (Fig. 2). Retrovirally encoded Myc mRNAs could be distinguished from endogenous $\mathrm{c}-\mathrm{M}$ yc by the size of the transcripts. With time in OHT 106ER, mRNA increased in abundance whereas the abundance of MycER mRN A decreased. Because MycER mRNA is transcribed from a constitutive promoter, the reduction in MycER with time in OHT is likely to be the result of negative selection, cells expressing MycER having a growth disadvantage, as described bel ow.

To see how constitutive Myc activity affected steady state mRNA levels of other members of the Myc network, we performed further $\mathrm{N}$ orthern blotting (Fig. 2). As reported previously (Gandarillas and Watt 1995), Mad levels were very low in preconfluent, adherent keratinocytes (KpBabe - OHT in Fig. 2), and barely detectable on blots. Mad was not induced by OHT in K106ER or KmycER. RNA from noninfected keratinocytes placed in suspension served as a positive control for Mad expression (data not shown; Gandarillas and Watt 1995). Max mRNA was detectable in all the samples, and the level was not altered by OHT treatment. In contrast, Mxi-1 mRNA levels were affected by OHT treatment, increasing in abundance in KmycER treated with $\mathrm{OHT}$ for 2 or 9 days (Fig. 2).

\section{Keratinocyte morphology and proliferation}

Keratinocytes expressing pBabe puro, c-Myc, M ycER, or 106ER were cultured in the presence or absence of OHT until confluence. Addition of OHT to KpBabe or K106ER had no obvious effect on cell morphology (Fig. 3A,E), and
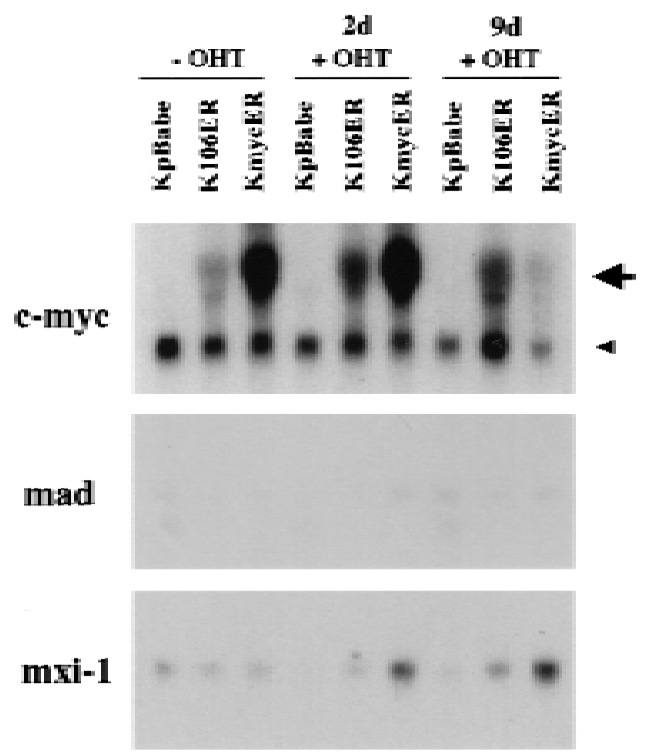

185

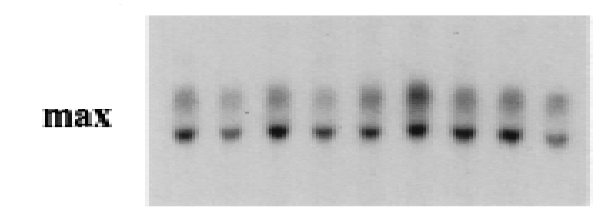

$\max$

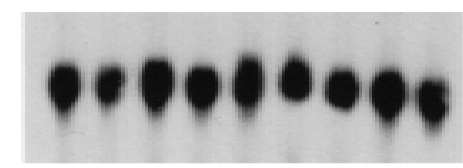

$18 \mathrm{~S}$

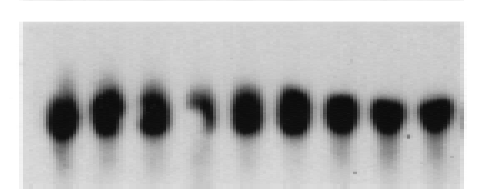

Figure 2. Expression of members of the Myc network. Total RNA was subjected to Northern blotting with the probes shown. The top $18 \mathrm{~S}$ panel is the control for C-M yc and M ax; the bottom $18 \mathrm{~S}$ panel is the control for Mad and Mxi-1. (Arrow) MycER or 106ER mRNA; (arrowhead) endogenous c-Myc MRNA.

KmycER grown in the absence of OHT also appeared normal (Fig. 3B). The morphology of cells expressing active c-Myc (i.e., Kmyc or KmycER plus OHT), however, was strikingly different from the controls (Fig. $3 C, D, F, G$ ). c-M yc-expressing cells were often I arger than the controls, with granular cytoplasm, and binucleate cells were frequently seen. The cells took Ionger to reach confluence, and confluent cultures were filled with highly refractile cells that detached into the culture medium, suggesting an acceleration of terminal differentiation (Fig. 3, cf. F and G with E).

The observation that c-Myc decreased keratinocyte proliferation was confirmed by construction of growth curves. KpBabe, K106ER, and KmycER were seeded at low density in the presence of OHT and cell number was measured as a function of time until the KpBabe cultures reached confluence (Fig. 4). In the presence of OHT, 
Figure 3. Cell morphology. (A-G) Phase contrast micrographs of preconfluent $(A-D)$ and confluent (E-G) keratinocytes. (A) KpBabe grown in the presence of OHT for 6 days; (B) KmycER, no OHT; (C) Kmyc, no OHT; (D) KmycER, 6 days OHT; (E) K106ER, 9 days OHT; (F) Kmyc, no OHT; (G) KmycER, 9 days OHT. Bar, $1 \mathrm{~mm}$.
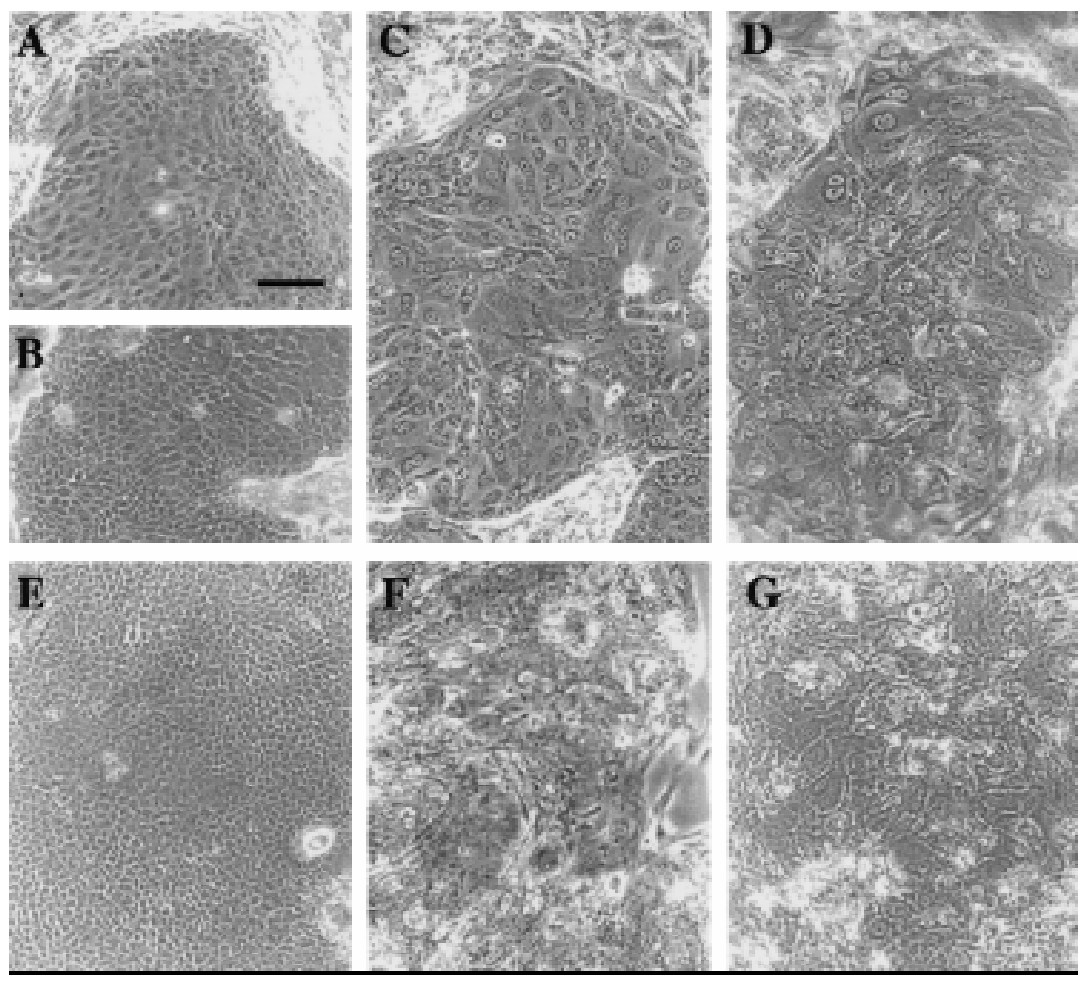

KmycER grew more slowly and reached saturation at a lower cell density than KpBabe. K106ER grew more rapidly than KpBabe and reached a higher confluent density, indicating that in this assay the mutant had a dominantnegative effect.

Because of the effects of 106ER and M ycER on growth rate, we examined whether there was any effect on the proportion of cells synthesizing DN A and the proportion of cells in different phases of the cell cycle. BrdU labeling established that the inhibitory effects of c-M yc and MycER did not reflect acceleration of the cell cycle or complete growth arrest, and that DN A synthesis was stimulated in K106ER (Table 1). DN A content was determined by flow cytometry of propidium iodide-labeled cells (Table 2). In the absence of OHT, the proportions of $\mathrm{G}_{1}$, $\mathrm{S}$, and $\mathrm{G}_{2}+\mathrm{M}$ cells were the same in KpBabe, K106ER, and KmycER populations and addition of OHT for 24 or $48 \mathrm{hr}$ had only small effects on cell cycle distribution (Table 2).

\section{A poptosis and terminal differentiation}

Because el evated c-M yc is known to induce apoptosis in a variety of cell types, we investigated whether this was also the case in the keratinocyte cultures and was thus responsible for the reduction in growth rate. The number of apoptotic deaths was first evaluated by video-lapse microscopy of keratinocytes expressing M ycER or 106ER (Fig. 5A ). OHT was either added at the time of filming or 2 days before, as shown schematically in Figure 5A. In one experiment, the effect of removing serum and growth factors was al so tested, because serum starvation is known to enhance apoptosis (Evan et al. 1992; Harrington et al. 1994). The number of apoptotic deaths was extremely small in all cases, and there was no effect of activating MycER with OHT. The time-lapse video observations were confirmed by a quantitative enzymelinked immunosorbent assay (ELISA) that detects cytoplasmic histone-associated DN A, a marker of apoptotic cells (Fig. 5B); in this case, suspended MDCK cells were used as a positive control (Frisch and Francis 1994).

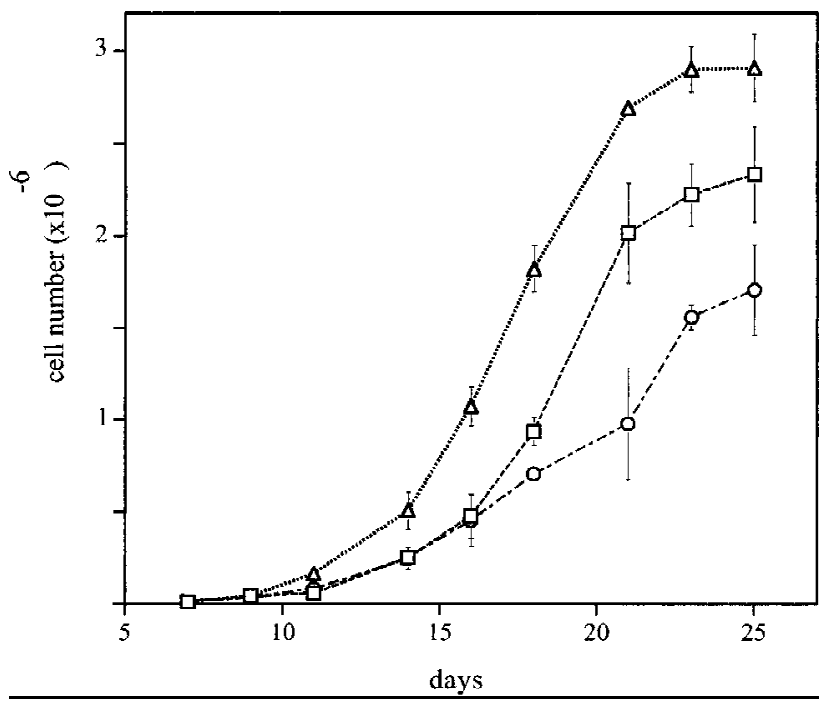

Figure 4. Growth curve. Cells were cultured in OHT throughout the experiment ( $\triangle$ K106ER; $(\square)$ KpBabe; ( $\bigcirc$ KmycER). Data shown are means of triplicate dishes \pm standard deviation. 
Table 1. BrdU labeling of S-phase keratinocytes

\begin{tabular}{lcccc}
\hline & $\begin{array}{c}-\mathrm{OHT} \\
(24 \mathrm{hr} \mathrm{BrdU})\end{array}$ & $\begin{array}{c}24 \mathrm{hr}+\mathrm{OHT} \\
(24 \mathrm{hr} \mathrm{BrdU})\end{array}$ & $\begin{array}{c}-\mathrm{OHT} \\
(3 \mathrm{hr} \mathrm{BrdU})\end{array}$ & $\begin{array}{c}48 \mathrm{hr}+\mathrm{OHT} \\
(3 \mathrm{hr} \mathrm{BrdU})\end{array}$ \\
\hline KpBabe & 68.5 & 67.2 & 28.8 & 28.9 \\
K106ER & 62.8 & 68.2 & 32.6 & 41.2 \\
KMycER & 69.7 & 58.1 & 36.1 & 20.5 \\
\hline
\end{tabular}

Cells grown in the presence or absence of $\mathrm{OHT}$ for 24 or $48 \mathrm{hr}$ were label ed for the length of time shown. Data are means of triplicate determinations.

Given the lack of c-Myc-induced apoptosis, another explanation for the reduced growth rate of KmycER and $\mathrm{Kmyc}$ is that c-M yc increases the rate of terminal differentiation. KpBabe, Kmyc, KmycER, and K106ER were grown in the presence or absence of OHT for 9 days. The proportion of cells in each population expressing involucrin, a marker of terminal differentiation, was determined by flow cytometry (Fig. 6A). The number of involucrin-positive cells was significantly greater in Kmyc and KmycER +OHT populations than in KpBabe, K106ER $\pm \mathrm{OHT}$, or KmycER in the absence of OHT.

The kinetics of the increase in differentiation are shown in Figure 6B, in which the proportion of involucrin-positive cells was determined, with time, after addition of $\mathrm{OHT}$. The increase was significant from day 5 onward. No increase in the number of involucrin-positive cells was seen in KmycER in the absence of OHT, nor in K106ER cells in the presence or absence of OHT. Constitutive expression of c-M yc had the same effect as OHT treatment of KmycER: the number of involucrinpositive cells in Kmyc was $44.5 \% 12$ days after infection, compared with $16.0 \%$ in KpBabe.

\section{c-Myc promotes exit from the stem cell compartment}

When keratinocytes are stimulated to differentiate by depriving integrins of bound ligand, irreversible inhibition of proliferation occurs within $5 \mathrm{hr}$ and the majority of cells become involucrin-posi tive within $24 \mathrm{hr}$ (Adams and Watt 1989). Both stem and transit-amplifying cells initiate involucrin expression in suspension without undergoing any rounds of division (Jones and Watt 1993). The kinetics of c-Myc-induced differentiation (Fig. 6B) and the absence of complete growth arrest are not consistent with a direct induction by c-Myc of cell cycle withdrawal and involucrin expression. Instead, the data would be compatible with a role for c-Myc in driving a transition from the stem to the transit amplifying compartment, because involucrin would be induced only as the transit amplifying divisions are completed over a period of days. To test this hypothesis, we examined the effects of c-M yc on the two available markers that distinguish stem cells and transit amplifying cells, namely, surface $\beta_{1}$ integrin levels and clonogenicity.

Keratinocytes were label ed with two anti-integrin antibodies: an antibody to the $\beta_{1}$ integrin subunit that detects all $\beta_{1}$ integrin heterodimers (primarily $\alpha_{2} \beta_{1}, \alpha_{3} \beta_{1}$, and $\alpha_{5} \beta_{1}$ ) and an antibody specific for $\alpha_{3} \beta_{1}$ (Jones and Watt 1993). Cells that were al ready undergoing terminal differentiation were gated out on the basis of physical parameters (forward and side scatter) so that only integrin levels on basal cells were measured (Jones and Watt 1993). We compared untreated K106ER and KmycER with cells grown for 3 days in the presence of $\mathrm{OHT}$; this time point was chosen because it was before the number of involucrin-positive KmycER had increased significantly (Fig. 6B). OHT treatment resulted in a twofold decrease in the modal fluorescence of KmycER labeled with anti- $\beta_{1}$ or anti- $\alpha_{3} \beta_{1}$ antibodies (Fig. 7 A,B), the same fold difference as reported previousl y to distingui sh stem from transit amplifying cells (Jones and Watt 1993). OHT did not affect $\beta_{1}$ levels in K106ER (Fig. 7C), but there was a slight increase in $\alpha_{3} \beta_{1}$ (Fig. 7D), and at later times total surface $\beta_{1}$ levels were al so increased (data not shown).

To anal yze the prol iferative potential of individual keratinocytes, KmycER and K106ER cells were seeded at clonal density, and OHT was added $24 \mathrm{hr}$ later. Fourteen days after plating, the dishes were fixed and stained to determine the total number of colonies per dish and the ratio of actively growing to abortive colonies (T able 3). Actively growing colonies were large and rounded with small basal cells; such colonies frequently had a darkly

Table 2. Proportion of cells in different phases of the cell cycle, determined by flow cytometry of propidium iodide-labeled cells

\begin{tabular}{|c|c|c|c|c|c|c|c|c|c|}
\hline \multicolumn{10}{|c|}{ DNA profile (\% of cells) } \\
\hline \multirow[b]{2}{*}{$\mathrm{OHT}$} & \multicolumn{3}{|c|}{ None } & \multicolumn{3}{|c|}{$24 \mathrm{hr}$} & \multicolumn{3}{|c|}{$48 \mathrm{hr}$} \\
\hline & $\mathrm{G}_{1}$ & $\mathrm{~S}$ & $\mathrm{G}_{2}+\mathrm{M}$ & $\mathrm{G}_{1}$ & S & $\mathrm{G}_{2}+\mathrm{M}$ & $\mathrm{G}_{1}$ & $\mathrm{~S}$ & $\mathrm{G}_{2}+\mathrm{M}$ \\
\hline KpBabe & 73.4 & 14.9 & 11.0 & 75.0 & 14.0 & 10.6 & 74.6 & 14.4 & 10.6 \\
\hline K106ER & 75.1 & 14.0 & 10.8 & 73.8 & 15.2 & 10.4 & 71.6 & 17.0 & 11.2 \\
\hline KmycER & 75.2 & 13.0 & 10.8 & 67.1 & 15.9 & 15.8 & 76.4 & 7.8 & 15.1 \\
\hline
\end{tabular}

Data are means of triplicate determinations. 
A

Figure 5. Apoptosis. (A) Time-lapse video analysis of apoptosis. (Top) Cells were grown in complete medium (FAD, FCS, and HICE, i.e., including serum and growth factors) without OHT for 4 days, transferred to fresh medium, and then filmed (T.V.) for 2 days in the presence of $\mathrm{OHT}$. (Bottom) Cells were grown in OHT throughout the experiment. After 1 day (asterisk), the medium was changed and replaced with either fresh complete medium (+serum/GF) or FAD without FCS + HICE (-serum/GF). After another day, the medium was changed and filming began (T.V.). Filming continued for 4 days. The number of keratinocytes per field was scored at the beginning of each recording period (start) and the total number of apoptotic deaths (dead) per field is shown for each recording period. The final number of cells per field could not be scored accurately because of stratification but was estimated as $\sim 1000$ for K106ER cells in complete medium and $\sim 500$ for K106ER cells in FAD without supplements. The final number of KmycER cells per field was slightly lower than that of K106ER (see Fig. 4). (B) Determination of apoptosis by measurement of cytoplasmic histone-associated DNA in an ELISA. K106ER and KMycER were treated with OHT for 6 days. Cells were grown in complete medium (serum/GF) or starved in FAD alone for $30 \mathrm{~h}$ prior to extraction. Values are OD $405 \mathrm{~nm}$. (Shaded boxes) tserum/GF; (solid boxes) - serum/GF.

B
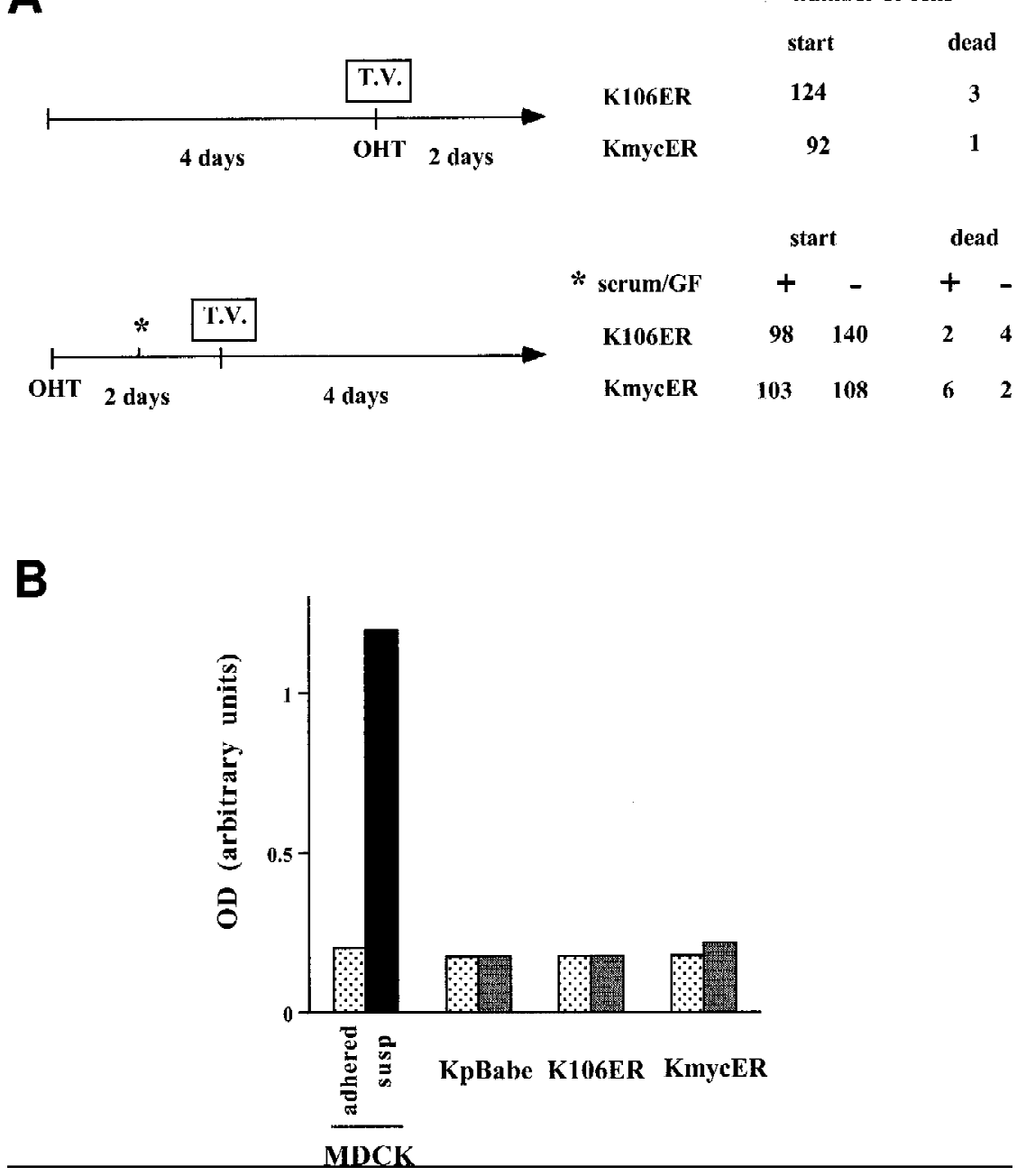

stained rim, reflecting displacement of J2-3T 3 cells (Fig. 8). Abortive colonies were smaller and were diffuse in morphology and contained only large cells; colonies of $<25-30$ cells were not scored (Fig. 8). N ote that this classification of abortive colonies differs from that of Jones and Watt (1993) in that the abortive colonies are larger; the present classification reflects the higher seeding density used in the experiments. The presence or absence of OHT did not have a significant effect on the total number of col onies founded by each cell population (T able 3 ). In the absence of OHT, 40\% of K106ER and KmycER clones were abortive; addi tion of OHT caused a decrease in the proportion of K106ER abortive clones and an increase in the proportion of KmycER abortive clones (Table 3).

To establish that the effect of Myc activation was selectivefor the stem cell compartment, we cultured KmyCER and K106ER in the absence of OHT and then fractionated the basal cells by fluorescence-activated cell sorting (FACS) into high or low $\beta_{1}$ integrin-expressing subpopulations, that is, enriched for stem cells or transit amplifying cells, respectively (Fig. 8). In the absence of $\mathrm{OHT}, \mathrm{KmycER}$ expressing high integrin levels were en- riched for cells that founded actively growing colonies (i.e., enriched stem cells), whereas KmycER expressing low integrin levels were enriched for cells that formed abortive colonies (transit amplifying cells); this is as reported previously for uninfected keratinocytes (Jones and Watt 1993). In contrast, when KmycER were grown in the presence of OHT, both the high and low integrinexpressing subpopulations gave rise predominantly to abortive colonies. The OHT effect was selective for KmycER because in OHT-treated K106ER cultures the high integrin-expressing population was still enriched for actively growing colonies.

Premature terminal differentiation in epidermis reconstructed on a dermal substrate

The reduction in integrin levels, the clonogenicity assays, and the kinetics of the increase in involucrin-positive cells are all consistent with the interpretation that constitutive activity of $\mathrm{Myc}$ is driving keratinocytes from the stem to the transit amplifying compartment. The limited degree of histological differentiation that can be achieved in keratinocyte cultures on tissue cul- 
A
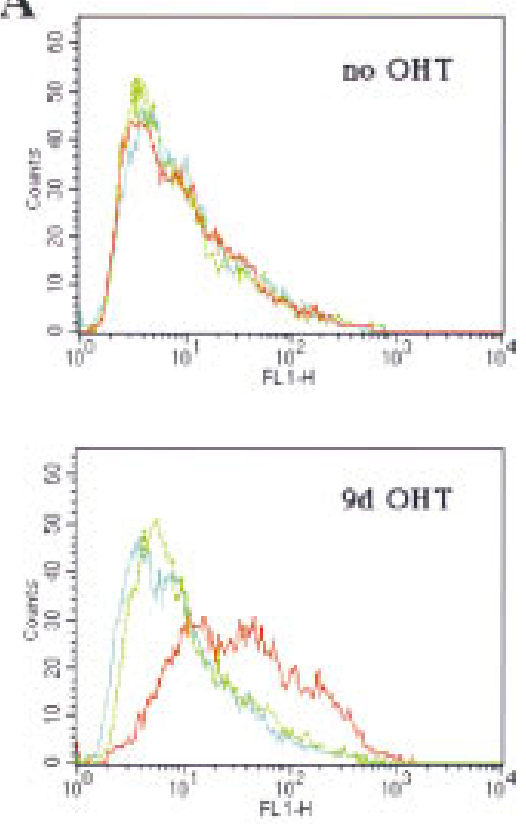

B

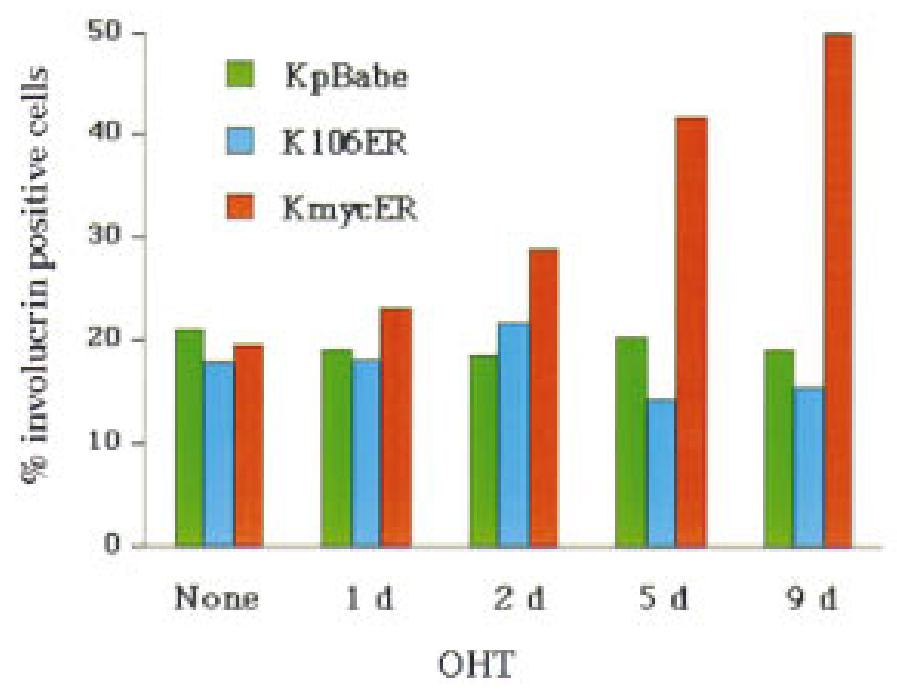

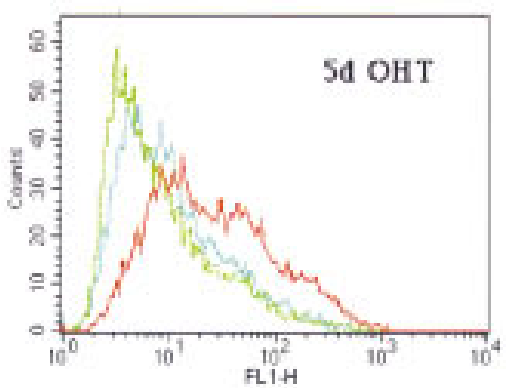

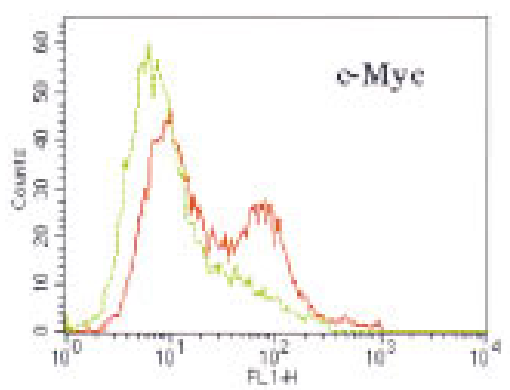

Figure 6. Terminal differentiation. (A) Flow cytometric analysis of the proportion of involucrin-positive cells. N o OHT, $5 d$ (5 day) OHT and 9d (9 day) OHT panels: (Green lines) KpBabe; (blue lines) K106ER; (red lines) KmycER. Cells were harvested after culture in the presence or absence of OHT for the number of days shown. c-M yc panel: (Green line) KpBabe; (red line) Kmyc. Cells were grown in the absence of OHT. (y-axes) Cell number, (x-axes) fluorescence (arbitrary units, log scale). Positive staining for involucrin corresponds to fluorescence of $>1.7 \times 10^{1}$ units. (B) Percent invoIucrin-positive cells measured in the absence of $\mathrm{OHT}$ or after addition of OHT for the number of days indicated. Cells from triplicate dishes were analyzed. Error bars show S.E.M . ture plastic prevents analysis of the complete terminal differentiation pathway; therefore, we seeded keratinocytes on dead, de-epi dermized dermis and cultured them at the air-medium interface to achieve a degree of histological differentiation that is as close as possible to epidermis in vivo (Pruniéras et al. 1983; Basset-Séguin et al. 1990; Rikimaru et al. 1997). If cells are being driven out of the stem cell compartment, there should be evidence of premature (accelerated) terminal differentiation and depletion of the proliferative population.

K106ER and KmycER were grown on dermis for 15 days either in absence of OHT or with OHT addition for the final 12 days. In hematoxylin and eosin-stained sections, the epidermis formed by K106ER appeared close to normal epidermis in vivo, with distinct and well organized basal, spinous, granular, and cornified layers (Fig. 9A). In contrast, the histology of the KmycER cultures was clearly abnormal, with decreased cellularity of the basal layer and gross expansion of the granular and cornified layers (Fig. 9B). KmycER cells in the spinous, granular, and cornified layers failed to flatten, and the boundaries between the different layers were perturbed.

The cultures were stained with antibodies to markers of proliferation and terminal differentiation. The proportion of basal cells stained positively for $\mathrm{Ki}-67$, a nuclear protein expressed by proliferating cells (Schlütter et al. 1993), was determined: $46.1 \%$ in K106ER and $29.8 \%$ in KmycER (Fig. 9C,D). In the absence of OHT, the proportion of Ki-67 positive cells was $36.2 \%$ in K106ER and $34.8 \%$ in KmycER. In dermal cultures of normal keratinocytes, involucrin expression is observed in all the suprabasal layers (Asselineau et al. 1989); this pattern was found in K106ER cultures (Fig. 9E), whereas in KmycER cultures clusters of involucrin-positive cells were 

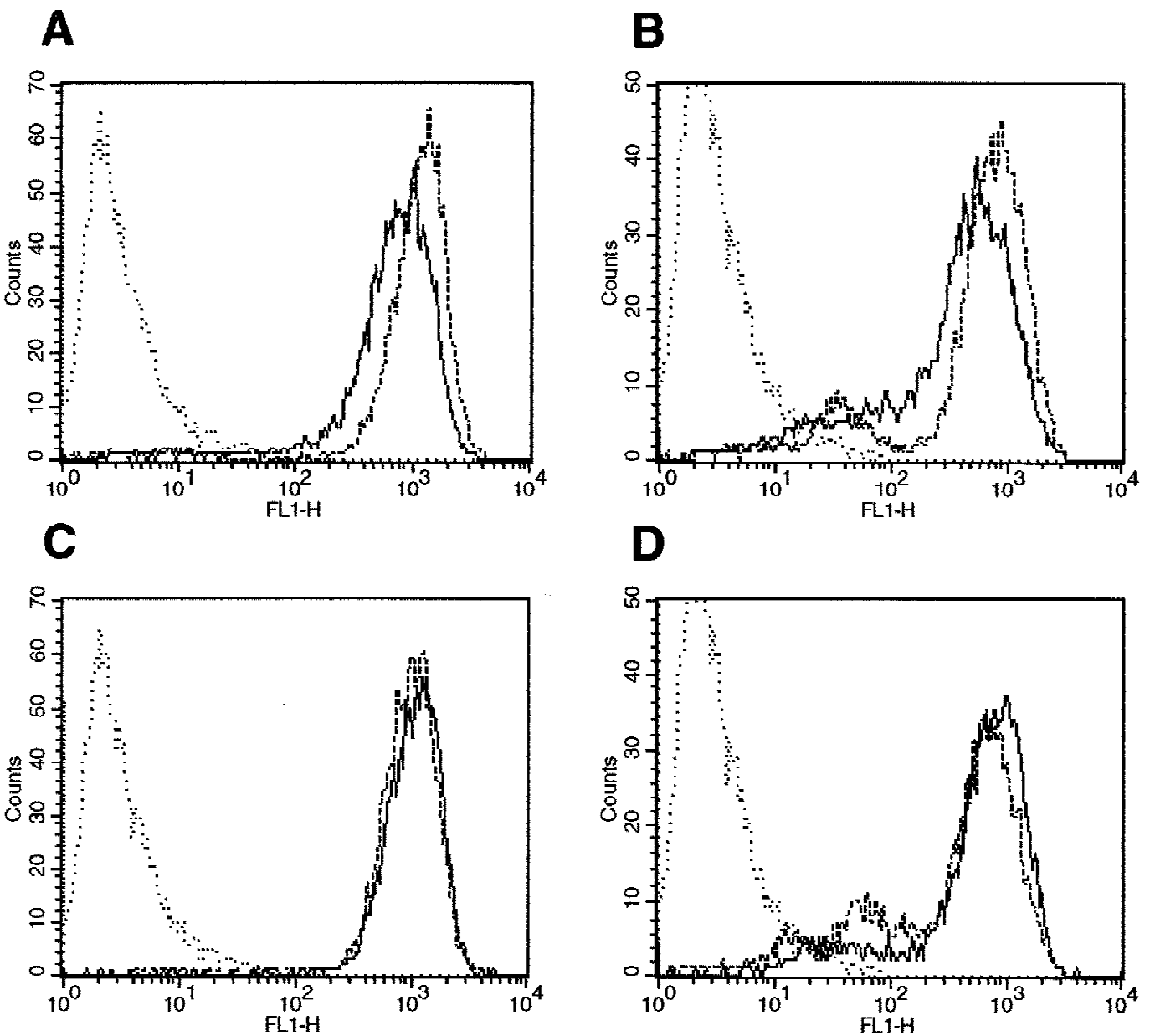

Figure 7. Flow cytometry of KmycER $(A, B)$ and K106ER $(C, D)$ cultured for 10 days with addition of OHT, where indicated, for the final 3 days. (Solid lines) +OHT; (broken lines) - OHT. (A,C) labeled with anti- $\beta_{1}$ integrin antibody. (B,D) labeled with anti- $\alpha_{3} \beta_{1}$ antibody. (A-D) (Dotted lines) Anti-CD8 (negative control). (y-axes) cell number. (x-axes) fluorescence in arbitrary units, log scale. Differentiated cells were gated out by forward and side scatter; fluorescence of basal (undifferentiated) cells is shown.

often found in the basal layer (Fig. 9F). K10 and Ioricrinpositive cells were al so found in the basal layer of KmyCER but not K106ER epidermis (data not shown). In K106ER cultures, expression of filaggrin, a marker of the granular layer (Dale et al. 1994), was confined to the uppermost viable cell layers (Fig. 9G), whereas the number of filaggrin-positive layers in MycER cultures was dramatically increased, extending to one to two layers above the basal layer (Fig. 9H). When cultures were al so stained with antibodies to c-M yc or the estrogen receptor, which recognize the MycER protein, we found expression of both MycER and 106ER in the nucleus of cells in all the viable layers (data not shown). KmycER and K106ER grown in the absence of OHT had a similar histological appearance to K106ER in the presence of OHT (data not shown).

\section{Discussion}

To the range of functions attributed to c-Myc, namely transformation, mitogenesis, and apoptosis, must now be added promotion of differentiation. Our experiments have shown that, in normal human epidermal keratinocytes, constitutive activity of c-M yc does not stimulate proliferation or apoptosis, but suppresses growth and stimulates terminal differentiation by promoting transition from the stem to the transit amplifying cell compartment. This is in contrast to the roles established for c-Myc in other cell types, namely stimulation of proliferation, suppression of differentiation, induction of apoptosis, and neoplastic transformation (DePinho et al. 1991; Morgenbesser and DePinho 1994; Packham and Cleveland 1995; Henricksson and Lüscher 1996). Although these results are unexpected, they are consistent with the concept that c-Myc plays a central role in determining the balance between cell growth, death, and differentiation, the consequences of overexpression be ing dependent on cellular context (Evan and Littlewood 1993). Our observations might explain why there are no reports of frequent c-Myc amplification or overexpression in spontaneous or chemically induced epidermal squamous cell carcinomas (T oftgard et al. 1985; Cooper 

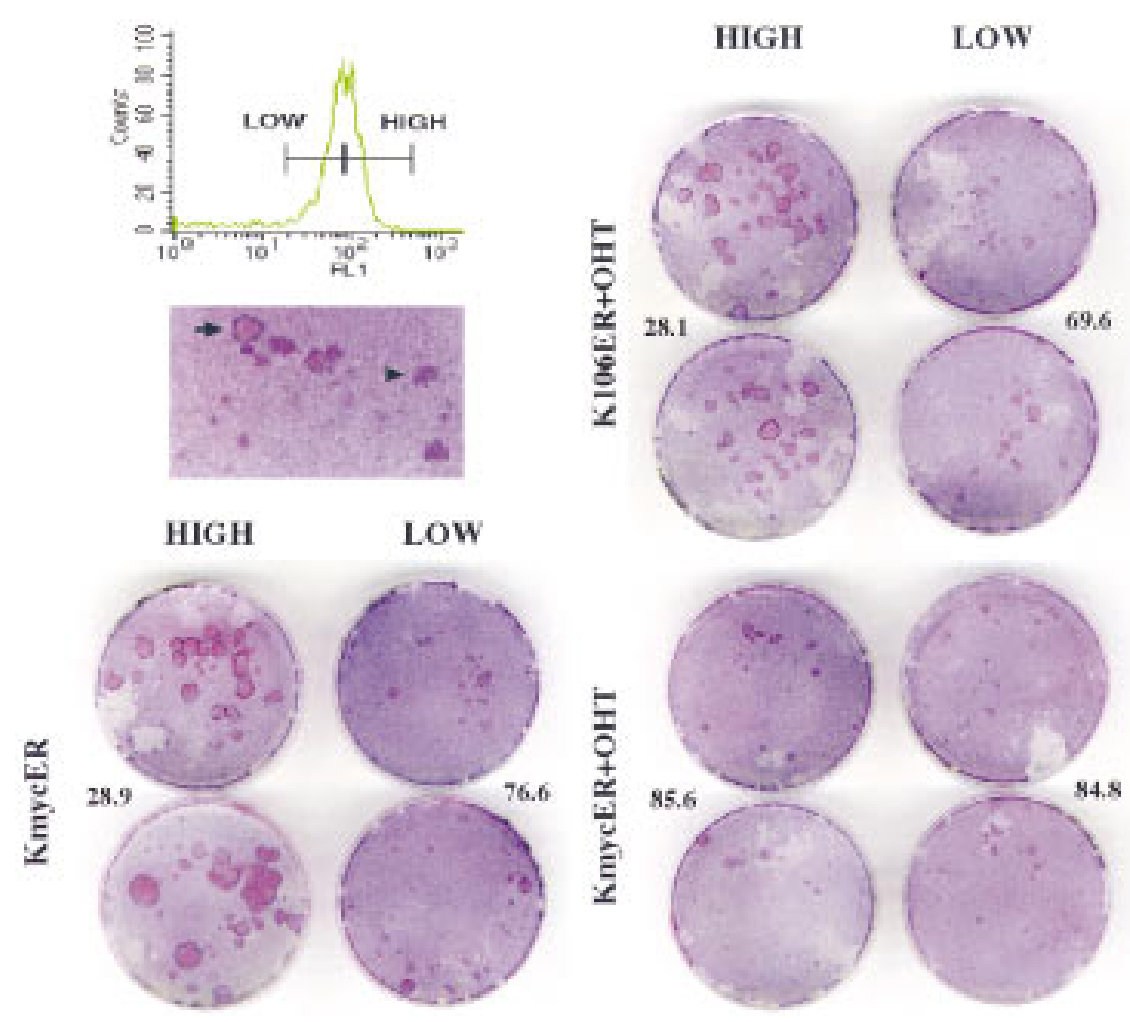

Figure 8. Clonogenicity of isolated stem and transit amplifying cells. K106ER and KMycER grown in the absence of OHT were harvested and labeled with an antibody to the $\beta_{1}$ integrin subunit; suprabasal cells were gated out and basal cells fractionated according to high or low integrin expression as indicated in the FACS profile. Cells were seeded at clonal density and cultured in the presence or absence of OHT. Duplicate 60-mm dishes are shown. N umbers are the percentage of abortive colonies (calculated from triplicate dishes). Insert below FACS profile shows an example of an actively growing clone (arrow) and an abortive clone (arrowhead) ( $\times 2.75)$.
1990) and why c-M yc does not contribute to skin carcinogenesis in vitro or in vivo, even when overexpressed in combination with Ras (Greenhal gh and Yuspa 1988; A. Balmain, pers. comm.).

To have confidence in the results, it is essential that all appropriate controls are in place. We made the same observations when we constitutively expressed wildtype c-M yc or OHT-activated MycER, even though the level of wild-type c-M yc was generally lower than that of $M$ ycER in infected cells. The ER construct had the major advantages that retrovirally infected keratinocytes were isolated without any interference as a result of activation of $\mathrm{Myc}$ function and that the kinetics of action of c-M yc could subsequently be monitored by time of exposure to OHT. OHT had no effect on keratinocytes that did not express the mutant receptor (KpBabe) and keratinocytes expressing MycER behaved in the same way as normal keratinocytes when OHT was absent. Deletion of amino acids 106-143 in the c-M yc transactivation domain prevented the induction of terminal differentiation, showing that c-Myc stimulates differentiation via its transcriptional regulatory domain.

Inappropriate expression of c-M yc induces apoptosis of a variety of cell types (for review, see Harrington et al. 1994; Packham and Cleveland 1995). Keratinocytes had an insignificant rate of apoptosis in the presence or absence of c-M yc, however, even when deprived of exogenous growth factors. Given that the cells were maintained in the presence of a feeder layer, and that keratinocytes are known to secrete a wide range of growth factors and cytokines (Kupper 1990; McKay and Leigh
1991), our observations do not completely rule out a role for c-M yc in keratinocyte apoptosis. Instead, the major significance of our finding is that increased terminal differentiation is not correlated with increased apoptosis, even though it has been argued frequently that keratinocyte terminal differentiation is a form of apoptosis (for review, see Polakowska and Haake 1994). Our observations are consistent with the finding that keratinocytes placed in suspension in the presence of growth factors are induced to differentiate, but not to apoptose (A dams and Watt 1989; A. Gandarillas, L.A. Goldsmith, and F.M. Watt, in prep.), in contrast to other epithelial cells (such as MDCK cells), which die by apoptosis in suspension (Frisch and Francis 1994; Ruoslahti and Reed 1994).

Our model, therefore, is that c-M yc drives keratinocytes from the stem to the transit amplifying proliferative compartment. The available markers of the transit compartment, namely limited prol iferative potential, reduced integrin expression, and increased probability of

Table 3. Analysis of colony formation by unfractionated cells

\begin{tabular}{lcc}
\hline & $\begin{array}{c}\text { Colony-forming efficiency } \\
(\%)\end{array}$ & $\begin{array}{c}\text { A bortive clones } \\
(\%)\end{array}$ \\
\hline K106ER & 12.7 & 41.1 \\
K106ER +OHT & 12.9 & 32.2 \\
KmycER & 10.9 & 42.7 \\
KmycER +OHT & 10.3 & 65.8 \\
\hline
\end{tabular}

Data are means of triplicate dishes. 

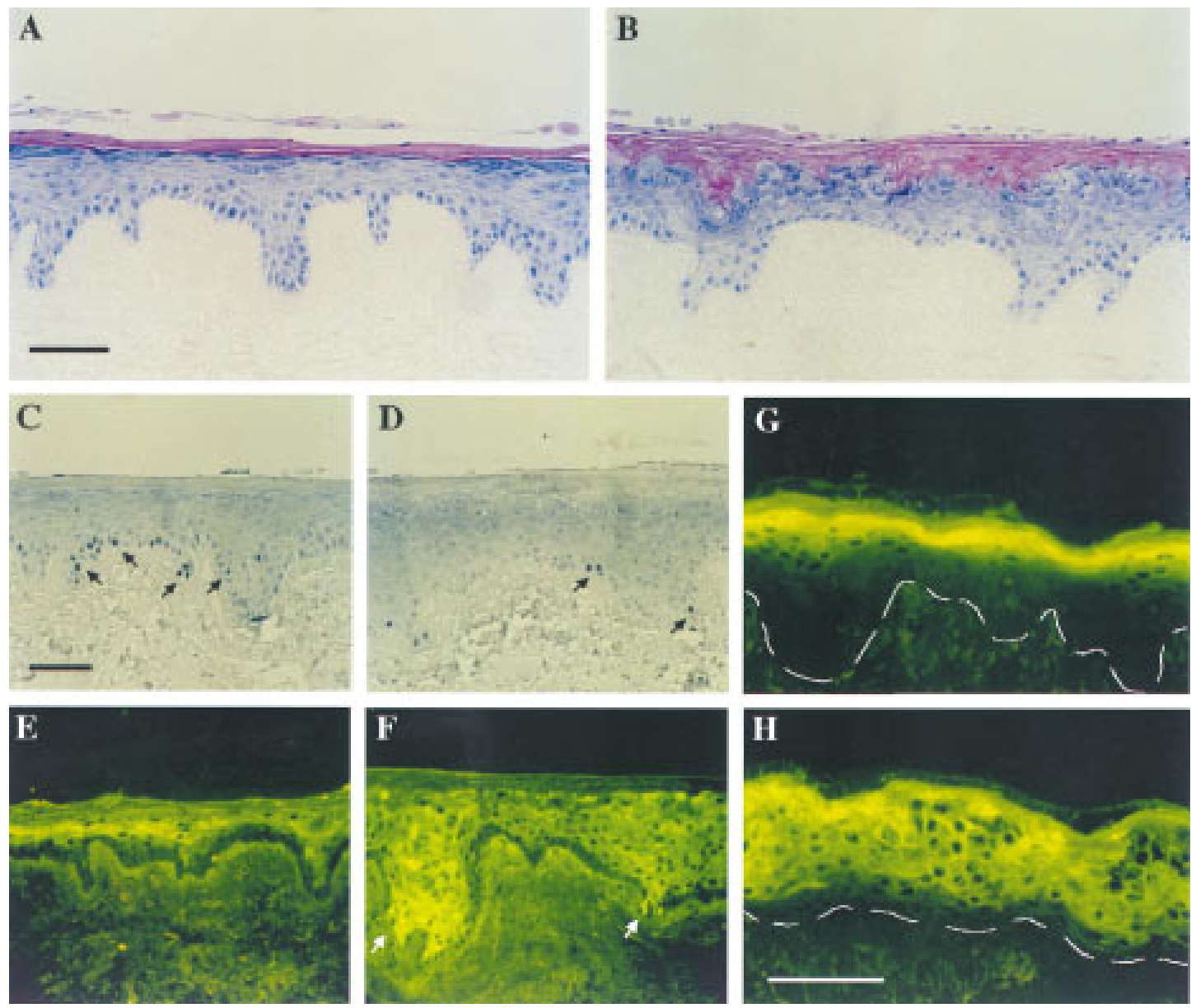

Figure 9. In vitro-reconstituted epidermis. Sections from epidermis reconstituted by cells expressing 106ER (A,C,E,G) or M ycER $(B, D, F, H)$ in the presence of $\mathrm{OHT}$. (A,B) hematoxylin/eosin staining; $(C, D)$ staining with an anti-Ki67 antibody; $(E, F)$ staining with anti-involucrin antibody; $(\mathrm{G}, \mathrm{H})$ staining with anti-filaggrin. Arrows in $\mathrm{C}$ and $\mathrm{D}$ indicate Ki-67-positive nuclei; arrows in $\mathrm{F}$ indicate involucrin-positive basal cells. Broken lines in $\mathrm{G}$ and $\mathrm{H}$ indicate position of basement membrane. Bar, $500 \mu \mathrm{m}$.

undergoing differentiation, are all features of the Kmyc and KmycER $+\mathrm{OHT}$ populations. The effects on proliferative potential were most striking when basal cells expressing high surface $\beta_{1}$ integrin levels (enriched for stem cells) were used for the clonogenicity assays, because OHT caused these cells to form abortive colonies in the KMycER dishes but not in K106ER, and had no effect on the cells expressing low integrin levels (enriched for transit amplifying cells). If cells are driven out of the stem cell compartment, the effect should be to deplete the basal layer of proliferating cells and induce premature terminal differentiation, as we observed in the cultures on dead, de-epidermized dermis (Fig. 9).

A nalysis of integrin levels and clonogenicity thus shows that c-M yc activation causes stem cell progeny to become transit amplifying cells. Constitutive activity of C-M yc affects the bal ance between stem cell renewal and terminal differentiation, rather than causing a complete block of either process. The effect of Myc activation on integrin levels is of particular interest, because it is possible that integrin genes are subject to transcriptional suppression by c-M yc (Judware and Culp 1995, 1997) and that high integrin levels are required for maintenance of the stem cell phenotype.

It seems reasonable to suggest that endogenous c-M yc has the same regulatory role as exogenous $\mathrm{Myc}$, given that the dominant-negative 106ER mutant interacts with endogenous $\mathrm{M}$ ax and stimulated growth and clonogenicity of unfractionated kerati nocytes. The 106ER mutant did not, however, inhibit initiation of terminal differentiation nor execution of the differentiation program on a dermal substrate. This may be because the mutant did not completely inhibit the activity of endogenous c-Myc or, alternatively, it may be because inhibition of c-M yc is not sufficient to keep cells within the stem cell compartment. Because inhibition of c-Myc by 106ER may be incomplete, we cannot rule out a requirement for c-Myc in maintaining keratinocytes within the cell cycle, as in other cell types (Henricksson and Lüscher 1996).

c-Myc expression is confined to basal (undifferentiated) keratinocytes and Mad and M Xi-1, two other heterodi merization partners of $M$ ax, are induced during terminal differentiation (Gandarillas and Watt 1995; Hurlin 
et al. 1995a,b; Västrik et al. 1995; Lymboussaki et al. 1996). M ycER was detectable in all the viable layers of epidermis reconstituted by culture on the dermal substrate and in involucrin-positive cells in cultures on tissue culture plastic (data not shown). Thus, although endogenous c-M yc is normally down-regulated during terminal differentiation, loss of c-M yc is not a prerequisite for initiation of terminal differentiation. In addition, whereas the level of $\mathrm{M}$ ad normally increases during keratinocyte terminal differentiation (Gandarillas and Watt 1995; Hurlin et al. 1995a,b; Västrik et al. 1995), $\mathrm{Mad}$ was not induced in differentiating KmycER; this suggests that c-M yc might repress mad transcription and indicates that el evated $M$ ad is not a prerequisite for terminal differentiation. In contrast, $\mathrm{M}$ xi-1 level s increased in OHT-treated KmycER, as in differentiating uninfected keratinocytes (Gandarillas and Watt 1995).

The level of c-M yc in the epidermis is very low (Hurlin et al . 1995a; Lymboussaki et al. 1996; A. Gandarillas and F. Watt, unpubl.), and our results suggest that an increase in c-M yc activity in individual stem cells would be sufficient to induce those cells to become transit amplifying cells and, thence, to undergo terminal differentiation. $\mathrm{c}-\mathrm{Myc}$ is the first factor that has been shown to regulate exit from the epidermal stem cell compartment, and identification of c-Myc target genes in keratinocytes, therefore, offers the exciting prospect of gaining further understanding of the control of stem cell fate.

\section{Materials and methods}

\section{Keratinocyte culture}

Primary human keratinocytes were isolated from neonatal foreskins of three different individuals (strains kq, km, z) and cultured in the presence of a feeder layer of J2-3T 3 cells in FAD medium [Ham's F12 medium/Dulbecco's modified Eagle medium (DMEM) (1:3), $1.8 \times 10^{-4} \mathrm{M}$ adenine] supplemented with $10 \%$ fetal calf serum (FCS) and a cocktail of $0.5 \mu \mathrm{g} / \mathrm{ml}$ of hydrocortisone, $5 \mu \mathrm{g} / \mathrm{ml}$ of insulin, $10^{-10} \mathrm{M}$ cholera enterotoxin, and $10 \mathrm{ng} / \mathrm{ml}$ of epidermal growth factor (HICE cocktail) as described previously (Rheinwald 1989; Watt 1994). J2-3T 3 cells were cultured in DMEM containing $10 \%$ donor calf serum.

Keratinocyte cultures on dermis were prepared as described by Rikimaru et al. (1997). The epidermis was removed from adult breast skin by heat treatment, and cells in the dermis were killed by repeated cycles of freezing and thawing. Keratinocytes $\left(10^{5}\right)$ in $15 \mu \mathrm{l}$ medium were seeded on the center of a $1.5-\mathrm{cm}^{2}$ piece of dermis and grown at the air-liquid interface on a metallic support.

\section{Retroviral vectors and packaging lines}

The following retroviral vectors were used: pBabe puro (empty vector; kind gift of $\mathrm{H}$. Land, ICRF, London, UK; M orgenstern and Land 1991); pBabe c-M yc 3 (wild-type c-M yc expressed under the control of the retroviral $5^{\prime}$ LTR; kind gift of $B$. Amati, ISREC, Lausanne, Switzerland); pBabe-myc ER and pBabe-106143 ER (c-M yc fusion proteins with the mutant estrogen receptor, G525R, expressed under the control of the retroviral 5' LTR; 106-143 ER contains a deletion of c-M yc amino acids 106-143; kind gifts of T. Littlewood; Littlewood et al. 1995). Twenty micrograms of each construct were transfected by calcium- phosphate precipitation, as described by M orgenstern and Land (1991), into GP +E ecotropic packaging cells. Two days after transfection, $2.5 \mu \mathrm{g} / \mathrm{ml}$ of puromycin was added to select retrovirus-producing cells.

Once stable GP +E transfectant lines had been obtained, the cells were rinsed and incubated in puromycin-free medium overnight. M edium conditioned in this way was harvested, centrifuged to remove any cells, and supplemented with $8 \mu \mathrm{g} / \mathrm{ml}$ of Polybrene. The conditioned medium was incubated with $2 \times 10^{5}$ amphotropic GP +env AM 12 packaging cells (M arkowitz et al. 1988) for 3-14 hr. Fresh medium was added to the infected AM 12 cells and 2 days later $2.5 \mu \mathrm{g} / \mathrm{ml}$ of puromycin was added for selection of retrovirus-producing cell lines. Polyclonal populations of infected AM 12 cells were used to infect keratinocytes. The retroviral packaging lines were grown in DMEM containing $10 \%$ FCS.

\section{Retroviral infection of keratinocytes}

Confluent $\mathrm{AM} 12$ cells producing the retroviral vectors were treated with $4 \mu \mathrm{g} / \mathrm{ml}$ of mitomycin $C$ for $2 \mathrm{hr}$ to irreversibly inhibit proliferation and then cocultured with third-passage human keratinocytes. Two days after plating keratinocytes, $1 \mu \mathrm{g} /$ $\mathrm{ml}$ of puromycin was added to select for infected cells. After at least 3 days, the AM 12 cells were removed and replaced with puromycin-resistant J2-3T 3 cells (prepared by transfection of J2-3T 3 cells with pBabe puro and kindly provided by L. Goodman, ICRF, London, UK). Infected keratinocytes were either used immediately for experiments, or after one or two passages in the presence of $1 \mu \mathrm{g} / \mathrm{ml}$ of puromycin and puromycin-resistant J2-3T 3 cells. Activation of steroid-induci ble constructs was performed by adding $100 \mathrm{~nm}$ 4-hydroxytamoxifen (Z) (Research Biochemicals International) to the culture medium.

\section{PAGE, Western blotting, and immunoprecipitation}

Preconfluent cultures of infected keratinocytes were lysed in PAGE sample buffer containing $\beta$-mercaptoethanol as described (Laemmli 1970). Twenty $\mu \mathrm{g}$ of Iysate (equivalent to $\sim 2 \times 10^{5}$ cells) were loaded per track onto 10\% SDS-PAGE gels (Laemmli 1970). Following electrophoresis, proteins were transferred to nitrocellulose (Millipore) by el ectroblotting for $2 \mathrm{hr}$ at $400 \mathrm{~mA}$ in $20 \%$ methanol, $0.03 \%$ SDS, $19.2 \mathrm{~mm}$ glycine, $2.5 \mathrm{~mm}$ Tris$\mathrm{HCl}$ at $\mathrm{pH}$ 8.7.

Immunoblotting was performed with mAb Mycl-9E10 (Evan et al. 1985) to detect Myc proteins. Briefly, blots were blocked with $2 \%$ skimmed milk powder (Marvel), incubated for $2 \mathrm{hr}$ with 9E10, washed, incubated with peroxidase-anti-mouse IgG for $1 \mathrm{hr}$, washed, and devel oped by use of the ECL system (Amersham). Washes were carried out in $10 \mathrm{~mm}$ Tris- $\mathrm{HCl}$ at $\mathrm{pH} 8.0$, $150 \mathrm{~mm} \mathrm{NaCl}, 2 \%$ skimmed milk powder, and 0.5\% Tween 20.

For immunoprecipitation, $10^{7}$ keratinocytes from preconfluent cultures were lysed in 1\% N P-40, $50 \mathrm{~mm}$ Tris $\mathrm{HCl}$ buffer containing $0.1 \mathrm{~mm}$ DTT, $10 \mu \mathrm{m}$ leupeptin, and $1 \mu \mathrm{m}$ pepstatin A. Soluble fractions were incubated with $1 \mu \mathrm{g}$ of anti-M ax antibody (Littlewood et al. 1992) for $2 \mathrm{hr}$ at $4^{\circ} \mathrm{C}$. Antibody complexes were collected after $1 \mathrm{hr}$ incubation with protein A-Sepharose at $4^{\circ} \mathrm{C}$ and washed five times in the lysis buffer. Complexes were boiled in PAGE sample buffer and fractionated in reducing $10 \%$ SDS-PAGE gels. Gels were transferred to nitrocellulose and immunoblotted with $9 \mathrm{E} 10$ anti-M yc antibody as above.

Immunohistochemistry

Cultures of infected keratinocytes grown on coverslips were rinsed in PBS, fixed in 3.87\% formal dehyde in PBS for $5 \mathrm{~min}$, 
washed with PBS, and permeabilized with methanol $\left(-20^{\circ} \mathrm{C}\right)$ for 5 min. mAb 9E10 diluted in PBS was added to the cells and incubated for $1 \mathrm{hr}$ at $37^{\circ} \mathrm{C}$. Coverslips were washed three times in PBS and incubated with secondary FITC-conjugated antimouse IgG (Jackson ImmunoResearch Labs. Inc.) for $45 \mathrm{~min}$. Coverslips were washed as before and mounted in Gelvatol (M onsanto Corp., USA). Immunostaining was analyzed with a Zeiss Axiophot fluorescence microscope.

Epidermis reconstructed by culturing keratinocytes on dead, de-epidermized dermis was either fixed in $3.87 \%$ formal dehyde in PBS and paraffin embedded, or embedded unfixed in OCT compound (Miles, Elkhart, USA), snap-frozen in an isopentane bath cooled in liquid nitrogen, and stored at $-70^{\circ} \mathrm{C}$. Paraffin sections were stained with hematoxylin and eosin, and labeled with anti-Ki-67 (N ovacastra) via the Streptavidin ABC (DAKO) detection system or with $\mathrm{DH} 1$ rabbit antiserum to involucrin (Dover and Watt 1987) and FITC conjugated anti-rabbit IgG. Frozen sections were label ed with anti-filaggrin (Biogenesis) and FITC conjugated anti-rabbit IgG. Antibody labeling conditions were as described above. To determine the proportion of Ki-67positive nuclei in basal keratinocytes, 400 cells per sample (consisting of two tissue sections) were scored.

\section{Northern blotting}

Total RN A was extracted by lysis of preconfluent cells in guandinium thiocyanate. Fifteen micrograms of RN A were loaded per track of a 1.8\% agarose gel and subjected to N orthern blotting by use of the protocol and probes described by Gandarillas and Watt 1995.

\section{Time-lapse video recording}

Frames were taken every 2 min. Olympus IMT1 or IMT2 inverted microscopes fitted with monochrome CCD cameras, video recorders (Sony M 370CE and PVW-2800P, respectively), and driven by Broadcast Animation Controllers (BAC 900) were used. Films were viewed on a SVHS video recorder linked to a 386 PC. The number of cells in each field was counted at the start of each experiment and estimated at the end. The number of cells undergoing apoptosis in each field was scored.

\section{Detection of cytoplasmic histone-associated DNA}

Keratinocytes were lysed in 0.5\% Triton X-100, 20 mM EDTA, $20 \mathrm{~mm}$ Tris at $\mathrm{pH} 7.4$ for $20 \mathrm{~min}$ on ice, spun at $20,000 \mathrm{~g}$ for 10 $\min$ at $4^{\circ} \mathrm{C}$, and the pellets discarded. Lysates of adherent MDCK cells or MDCK cells that had been suspended in $0.3 \%$ agar for $6 \mathrm{hr}$ (positive control) were kindly provided by Asim Khwaja (ICRF, London, UK). Lysates from $10^{3}$ cells per sample were subjected to a Cell Death Detection ELISA (Boehringer Mannheim), which detects histone-DNA complexes by antihistone antibody and peroxidase-anti-DNA conjugated antibody. Peroxidase activity was developed for $20 \mathrm{~min}$ and the color of the samples was determined by spectrophotometry at $405 \mathrm{~nm}$.

\section{Analysis of terminal differentiation}

Infected keratinocytes were harvested with trypsin/EDTA. Aliquots of $10^{6}$ cells were washed once with PBS and then fixed in $1 \%$ freshly thawed paraformal dehyde in PBS for $10 \mathrm{~min}$ at room temperature. Cells were then washed and permeabilized in $0.3 \%$ saponin (Sigma) in PBS for $20 \mathrm{~min}$ at room temperature. The saponin was diluted 1:2 with PBS, and the cells were recovered by centrifugation. Cells were incubated in $100 \mu$ of SY 5 anti-involucrin monoclonal antibody (Hudson et al. 1992) in FSP (10\% FCS, $0.1 \%$ saponin in PBS) for $10 \mathrm{~min}$ at room temperature; cells were also incubated with anti-CD8 antibody (Sigma) or FSP al one as negative controls. After incubation, cells were washed twice with FSP and incubated with FITC-conjugated anti-mouse IgG in FSP. After two washes in FSP, cells were resuspended in $500 \mu \mathrm{l}$ of PBS and filtered through a $63-\mu \mathrm{m}$ nylon mesh (R. Cadish and Sons, London, UK). When DNA profiles were required, cells were spun down and resuspended in $10 \mu \mathrm{g} / \mathrm{ml}$ of propidium iodide. Cells were analyzed by flow cytometry on a Becton-Dickinson FACScan. Aggregates and debris were gated out; 10,000 gated events were acquired in list mode for every sample.

\section{BrdU incorporation}

Infected keratinocytes were incubated with $10 \mu \mathrm{m} \mathrm{BrdU}$ at $37^{\circ} \mathrm{C}$ and then harvested with trypsin/EDTA. Aliquots of $10^{6}$ cells were washed once with PBS and fixed in $70 \%$ ice-cold ethanol for $30 \mathrm{~min}$, vortexing for the first min. The cells were spun down and stained for BrdU, essentially as described previously (M cN ally and Wilson 1990). Briefly, cells were treated with $2 \mathrm{M}$ hydrochloric acid for $30 \mathrm{~min}$, washed in PBS, and incubated in anti-BrdU antibody (Sera-lab Ltd.), washed again and incubated in FITC anti-mouse IgG (DAKO), washed and treated with 1 $\mathrm{mg} / \mathrm{ml}$ of ribonuclease for $15 \mathrm{~min}$. The washing and antibodyincubation buffers consisted of $10 \%$ FCS, $0.2 \%$ Tween $20,0.1 \%$ BSA in PBS. $10 \mu \mathrm{g} / \mathrm{ml}$ of propidium iodide was added to the cells and flow cytometric analysis was carried out as described above. Fifteen thousand gated events were acquired for every sample.

\section{Growth and clonogenicity assays}

Stocks of keratinocytes to be used in these assays were grown in the absence of OHT. For growth curves, 1000 cells were plated per 35-mm dish in the presence of mitomycin C-treated J2-3T3. Twenty four hours after plating, OHT was added and after 1 week, cells from triplicate dishes were harvested every 2 days for up to 25 days.

For clonogenicity assays, 900 unfractionated keratinocytes or 500 sorted keratinocytes were plated per $60-\mathrm{mm}$ petri dish, in triplicate, in medium without $\mathrm{OHT}$. OHT was added to the medium of some of the cultures 1 day later. After 14 days $\pm \mathrm{OHT}$, the cultures were washed with PBS and the cells fixed in $3.87 \%$ formaldehyde for $5 \mathrm{~min}$ at room temperature. After further washing in PBS, the cultures were stained for 30 min at room temperature with Rhodanile blue (Rheinwald and Green 1975). All the visible colonies (i.e., $>0.4 \mathrm{~mm}$ in diameter and $>25-30$ cells) were scored on every dish.

\section{FACS and flow cytometry}

Preconfluent cultures of K106ER and KmycER grown in the absence of OHT were harvested with tryspin/EDTA, labeled with P5D2, as described below, and sorted with a Becton-Dickinson FACStar Plus. Suprabasal cells were gated out on the basis of their physical properties (Jones and Watt 1993) and basal cells expressing high or low levels of $\beta_{1}$ integrins were selected as shown in Figure 8.

For flow cytometry, K106ER and KmycER were cultured for 10 days with $\mathrm{OHT}$ being added, where appropriate, for the last 3 days. The cells were harvested and incubated on ice with P5D2 (mouse anti- $\beta_{1}$ integrin antibody; Dittel et al. 1993), or VM-2 (mouse anti- $\alpha_{3} \beta_{1}$ antibody; Kaufmann et al. 1989), or antiCD8 (Sigma) on ice for $20 \mathrm{~min}$. Cells were washed in PBSABC and incubated with FITC-conjugated goat anti-mouse IgG as 
before. Flow cytometry was carried out essentially as described by Jones and Watt (1993) and basal cells were sel ected for analysis on the basis of their forward and side scatter characteristics (Jones and Watt 1993).

\section{Acknowledgments}

We are especially grateful to T. Littlewood and to the following people for generous gifts of time and reagents: D. Davies, C. Gilbert, C. Hughes, A. Khwaja, G. Evan, B. Amati, and H. Land. We al so thank the Histopathology U nit for technical assistance and W. Senior for typing the manuscript. A. Gandarillas was supported by a Training Fellowship from the European Union and by an Imperial Cancer Research Fund Fellowship.

The publication costs of this article were defrayed in part by payment of page charges. This article must therefore be hereby marked "advertisement" in accordance with 18 USC section 1734 solely to indicate this fact.

\section{References}

Adams, J.C. and F.M. Watt. 1989. Fibronectin inhibits the terminal differentiation of human keratinocytes. Nature 340: 307-309.

Alarcon, R.M., B.A. Rupnow, T.G. Graeber, S.J. Knox, and A.J. Giaccia. 1996. Modulation of c-Myc activity and apoptosis in vivo. Cancer Res. 56: 4315-4319.

Alexandrow, M.G., M. Kawabata, M. Aakre, and H.L. Moses. 1995. Overexpression of the c-M yc oncoprotein blocks the growth-inhibitory response but is required for the mitogenic effects of transforming growth factor $\beta_{1}$. Proc. Natl. Acad. Sci. 92: 3239-3243.

Amati, B. and H. Land. 1994. Myc-M ax-Mad: A transcription factor network controlling cell cycle progression, differentiation and death. Curr. Opin. Genet. Dev. 4: 102-108.

Askew, D., R.A. Ashmun, B.C. Simmons, and J.L. Cleveland. 1991. Constitutive c-myc expression in an IL-3-dependent myel oid cell line suppresses cell cycle arrest and accelerates apoptosis. Oncogene 6: 1915-1922.

Asselineau, D., B.A. Bernard, C. Bailly, and M. Darmon. 1989. Retinoic acid improves epidermal morphogenesis. Dev. Biol. 133: 322-335.

Basset-Séguin, N., J.F. Culard, C. Kerai, F. Bernard, A. Watrin, J. Demaille, and J.J. Guilhou. 1990. Reconstituted skin in culture: A simple method with optimal differentiation. Differentiation 44: 232-238.

Blackwood, E.M., T.G. Lugo, L. Kretzner, M.W. King, A.J. Street, O.N. Witte, and R.N. Eisenman. 1994. Functional analysis of the AUG- and CUG-initiated forms of the c-M yc protein. Mol. Biol. Cell 5: 597-609.

Cañelles, M., M.D. Del gado, K.M. Hyland, A. Lerga, C. Richard, C.V. Dang, and J. Léon. 1997. Max and inhibitory c-M yc mutants induce erythroid differentiation and resistance to apoptosis in human myeloid leukemia cells. Oncogene 14: 1315-1327.

Chin, L., N. Schreiber-Agus, I. Pellicer, K. Chen, H-W. Lee, M. Dudast, C. Cordon-Cardo, and R.A. DePinho. 1995. Contrasting roles for $\mathrm{Myc}$ and $\mathrm{M}$ ad proteins in cellular growth and differentiation. Proc. Natl. Acad. Sci. 92: 8488-8492.

Cooper, G.M. 1990. Oncogenes. Pub. Jones and Bartlett, Boston. pp. 1-323.

Dale, B.A., K.A. Resing, and R.B. Presland. 1994. Keratohyalin granule proteins. In The keratinocyte handbook, (ed. I.M Leigh, E.B. Lane, and F.M. Watt), pp. 323-350. Cambridge University Press, Cambridge, UK.
Dang, C.V., M. McGuire, M. Buckmire, and W.M. Lee. 1989. Involvement of the "leucine zipper" region in the oligomerization and transforming activity of human c-myc protein. Nature 337: 664-666.

Danielian, P.S., R. White, S.A. Hoare, S.E. Fawell, and M.G. Parker. 1993. Identification of residues in the estrogen receptor that confer differential sensitivity to estrogen and hydroxytamoxifen. Mol. Endocrinol. 7: 232-240.

DePinho, R.A., N. Schreiber-A gus, and F.W. Alt. 1991. myc family oncogenes in the development of normal and neoplastic cells. Adv. Cancer Res. 57: 1-46.

Dittel, B.N., J.B. McCarthy, E.A. Wayner, and T.W. LeBien. 1993. Regulation of human B-cell precursor adhesion to bone marrow stromal cells by cytokines that exert opposing effects on the expression of vascular cell adhesion molecule-1 (VCAM-1). Blood 81: 2272-2282.

Dover, R. and F.M. Watt. 1987. Measurement of the rate of epidermal terminal differentiation: Expression of involucrin by S-phase keratinocytes in culture and in psoriatic plaques. J. Invest. Dermatol. 89: 349-352.

Evan, G.I. and T.D. Littlewood. 1993. The role of c-myc in cell growth. Curr. Opin. Genet. Dev. 3: 44-49.

Evan, G.I., A.H. Wyllie, C.S. Gilbert, T.D. Littlewood, H. Land, M. Brooks, C.M. Waters, L.Z. Penn, and D.C. Hancock. 1992. Induction of apoptosis in fibroblasts by c-myc protein. Cell 69: 119-128.

Evan, G.I., G.K. Lewis, G. Ramsay, and J.M. Bishop. 1985. Isolation of monoclonal antibodies specific for human c-myc proto-oncogene product. Mol. Cell Biol. 5: 3610-3616.

Frisch, S.M. and H. Francis. 1994. Disruption of epithelial cellmatrix interactions induces apoptosis. J. Cell Biol. 124: 619626.

Fuchs, E. and C. Bryne. 1994. The epidermis: Rising to the surface. Curr. O pin. Genet. Dev. 4: 725-736.

Gandarillas, A. and F.M. Watt. 1995. Changes in expression of members of the fos and jun families and myc network during terminal differentiation of human keratinocytes. Oncogene 11: 1403-1407.

Greenhalgh, D.A. and S.H. Yuspa. 1988. Malignant conversion of murine squamous papilloma cell lines by transfection with the fos oncogene. Mol. Carcinog. 1: 134-143.

Hall, P.A. and F.M. Watt. 1989. Stem cells: The generation and maintenance of cellular diversity. Development 106: 619633.

Hann, S.R., M. Dixit, R.C. Sears, and L. Sealy. 1994. The alternatively initiated C-M yc proteins differentially regulate transcription through a noncanonical DNA-binding site. Genes \& Dev. 8: 2441-2452.

Harrington, E.A., A. Fanidi, and G.I. Evan. 1994. Oncogenes and cell death. Curr. Opin. Genet. Dev. 4: 120-129.

Hashiro, M., K. Matsumoto, H. Okumura, K. Hashimoto, and K. Yoshikawa. 1991. Growth inhibition of human keratinocytes by antisense c-myc oligomer is not coupled to induction of differentiation. Biochem. Biophys. Res. Comm. 174: $287-292$

Henriksson, M. and B. Lüscher. 1996. Proteins of the Myc network: Essential regulators of cell growth and differentiation. Adv. Cancer Res. 68: 109-182.

Hudson, D.L., K.L. Weiland, T.P. Dooley, M. Simon, and F.M. Watt. 1992. Characterisation of eight monoclonal antibodies to involucrin. Hybridoma 11: 367-379.

Hurlin, P.J., K.P. Foley, D.E. Ayer, R.N . Eisenman, D. Hanahan, and J.M. Arbeit. 1995a. Regulation of Myc and Mad during epidermal differentiation and HPV-associated tumorigenesis. Oncogene 11: 2487-2501.

Hurlin, P.J., C. Quéva, P.J. Koskinen, E. Steingrímsson, D.E. 
Ayer, N.G. Copeland, N.A. Jenkins, and R.N. Eisenman. 1995b. Mad3 and Mad4: Novel Max-interacting transcriptional repressors that suppress c-myc dependent transformation and are expressed during neural and epidermal differentiation. EMBO J. 14: 5646-5659.

Jones, P.H. and F.M. Watt. 1993. Separation of human epi dermal stem cells from transit amplifying cells on the basis of differences in integrin function and expression. Cell 73: 713724.

Jones, P.H., S. Harper, and F.M. Watt. 1995. Stem cell patterning and fate in human epidermis. Cell 80: 83-93.

Judware, R. and L.A. Culp. 1995. Over-expression of transfected $\mathrm{N}$-myc oncogene in human SKNSH neuroblastoma cells down-regulates expression of $\beta_{1}$ integrin subunit. Oncogene 11: 2599-2607.

- - 1997. Concomitant down-regulation of expression of integrin subunits by $\mathrm{N}$-myc in human neuroblastoma cells: Differential regulation of $\alpha 2, \alpha 3$ and $\beta 1$. Oncogene 14: 13411350.

Kaufmann, R., D. Frösch, C. Westphal, L. Weber, and C.E. Klein. 1989. Integrin VLA-3: UItrastructural Iocalization at cellcell contact sites of human cell cultures. J. Cell Biol. 109: 1807-1815.

Kupper, T.S. 1990. The activated keratinocyte: A model for inducible cytokine production by non-bone marrow-derived cells in cutaneous inflammatory and immune responses. J. Invest. Dermatol. 94: 146S-150S.

Laemmli, U.K. 1970. Cleavage of structural proteins during the assembly of the head of bacteriophage $\mathrm{T}_{4}$. Nature 227: 680685.

Lee, L.A., C. Dolde, J. Barrett, C.S. Wu, and C.V. Dang. 1996. A link between c-M yc-mediated transcriptional repression and neoplastic transformation. J. Clin. Invest. 97: 1687-1695.

Li, L., C. Nerlov, G. Prendergast, D. M acGregor, and E.B. Ziff. 1994. c-Myc represses transcription in vivo by a novel mechanism dependent on the initiator el ement and $M y c$ box II. EMBO J. 13: 4070-4079.

Littlewood, T.D., B. Amati, H. Land, and G.I. Evan. 1992. Max and c-M yc/M ax DN A-binding activities in cell extracts. Oncogene 7: 1783-1792.

Littlewood, T.D., D.C. Hancock, P.S. Danielian, M.G. Parker, and G.I. Evan. 1995. A modified oestrogen receptor ligandbinding domain as an improved switch for the regulation of heterologous proteins. Nucleic Acids Res. 23: 1686-1690.

Lymboussaki, A., A. Kai painen, E. Hatva, I. Västrik, L. Jeskanen, M. Jalkanen, S. Werner, F. Stanbäck, and R. Alitalo. 1996. Expression of $\mathrm{Mad}$, an antagonist of $\mathrm{Myc}$ oncoprotein function, in differentiating keratinocytes during tumorigenesis of the skin. Br. J. Cancer 73: 1347-1355.

Markowitz, D., S. Goff, and A. Bank. 1988. Construction and use of a safe and efficient amphotropic packaging cell line. Virology 167: 400-406.

M cKay, I.A. and I.M. Leigh. 1991. Epidermal cytokines and their role in cutaneous wound healing. Br. J. Dermatol. 124: 513518.

McN ally, N.J. and G.D. Wilson. 1990. Measurement of tumour cell kinetics by the bromodeoxyuridine method. In Flow cytometry. A practial approach. (ed. M.G. Ormerod), pp. 87104. IRL Press, Oxford, UK.

M orgenbesser, S.D. and R.A. DePinho. 1994. Use of transgenic mice to study myc family gene function in normal mammalian development and in cancer. Semin. Cancer Biol. 5: 2136.

M orgenstern, J.P. and H. Land. 1991. Choice and manipulation of retroviral vectors. Methods Mol. Biol. 7: 181-206.

Packham, G. and J.L. Cleveland. 1995. c-Myc and apoptosis.
Biochim. Biophys. Acta 1242: 11-28.

Pietenpol, J.A., J.T. Holt, R.W. Stein, and H.L. Moses. 1990. Transforming growth factor $\beta 1$ suppression of c-myc gene transcription: Role in inhibition of keratinocyte proliferation. Proc. Natl. Acad. Sci. 87: 3758-3762.

Polakowska, R.R. and A.R. Haake. 1994. A poptosis: The skin from a new perspective. Cell Death Differ. 1: 19-31.

Potten, C.S. and R.J. M orris. 1988. Epithelial stem cells in vivo. J. Cell Sci. (Suppl.) 10: 45-62.

Pruniéras, M., M. Réginier, and D. Woodley. 1983. M ethods for cultivation of keratinocytes with an air-liquid interface. J. Invest. Dermatol. 81: 28S-33S.

Rheinwald, J. G. 1989. Methods for clonal growth and serial cultivation of normal human epidermal keratinocytes and mesothelial cells. In Cell growth and division. A practical approach (ed. R. Baserga), pp. 81-94. IRL Press, Oxford, UK.

Rheinwald, J.G. and H. Green. 1975. Formation of a keratinizing epithelium in culture by a cloned cell line derived from a teratoma. Cell 6: 317-330.

Rikimaru, K., J-P. Molès, and F.M. Watt. 1997. Correlation between hyperproliferation and suprabasal integrin expression in human epidermis reconstituted in culture. Exp. Dermatol. 6: 214-221.

Ruoslahti, E. and J.C. Reed. 1994. Anchorage dependence, integrins, and apoptosis. Cell 77: 477-478.

Sawyers, C.L., W. Callahan, and O.N. Witte. 1992. Dominant negative MYC blocks transformation by $A B L$ oncogenes. Cell 70: 901-910.

Schlütter, C., M. Duchrow, C. Wohlenberg, M.H.G. Becker, G. Key, H-D. Flad, and J. Gerdes. 1993. The cell proliferationassociated antigen of antibody Ki-67: A very large, ubiquitous nuclear protein with numerous repeated el ements, representing a new kind of cell cycle-maintaining proteins. J. Cell Biol. 123: 513-522.

Spotts, G.D., S.V. Patel, Q. Xiao, and S.R. Hann. 1997. Identification of downstream-initiated c-Myc proteins which are dominant-negative inhibitors of transactivation by fulllength C-M yc proteins. Mol. Cell. Biol. 17: 1459-1468.

Toftgard, R., D.R. Roop, and S.H. Yuspa. 1985. Proto-oncogene expression during two-stage carcinogenesis in mouse skin. Carcinogenesis 6: 655-657.

Västrik, I., A. Kaipainen, T-L. Penttilä, A. Lymboussakis, R. Alitalo, M. Parvinen, and K. Alitalo. 1995. Expression of the mad gene during cell differentiation in vivo and its inhibition of cell growth in vitro. J. Cell Biol. 128: 1197-1208.

Watt, F.M. 1989. Terminal differentiation of epidermal keratinocytes. Curr. Opin. Cell Biol. 1: 1107-1115.

- - - 1994. Cultivation of human epidermal keratinocytes with a 3T 3 feeder layer. In Cell biology: A laboratory handbook (ed. J.E. Celis), pp. 83-89. Cambridge University Press, Cambridge, UK.

Yaar, M., A. Gilani, P.J. DiBenedetto, D.D. Harkness, and B.A. Gilchrest. 1993. Gene modulation accompanying differentiation of normal versus malignant keratinocytes. Exp. Cell Res. 206: 235-243.

Younus, J. and B.A. Gilchrest. 1992. Modulation of mRN A levels during human keratinocyte differentiation. J. Cell Physiol. 152: 232-239. 


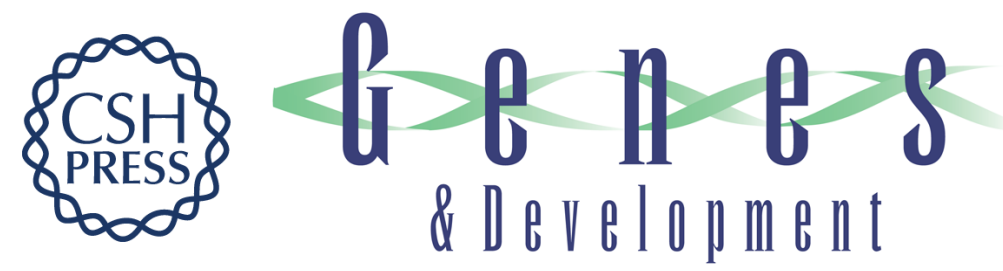

\section{c-Myc promotes differentiation of human epidermal stem cells}

Alberto Gandarillas and Fiona M. Watt

Genes Dev. 1997, 11:

Access the most recent version at doi:10.1101/gad.11.21.2869

References This article cites 59 articles, 14 of which can be accessed free at: http://genesdev.cshlp.org/content/11/21/2869.full.html\#ref-list-1

License

Email Alerting Receive free email alerts when new articles cite this article - sign up in the box at the top Service right corner of the article or click here.

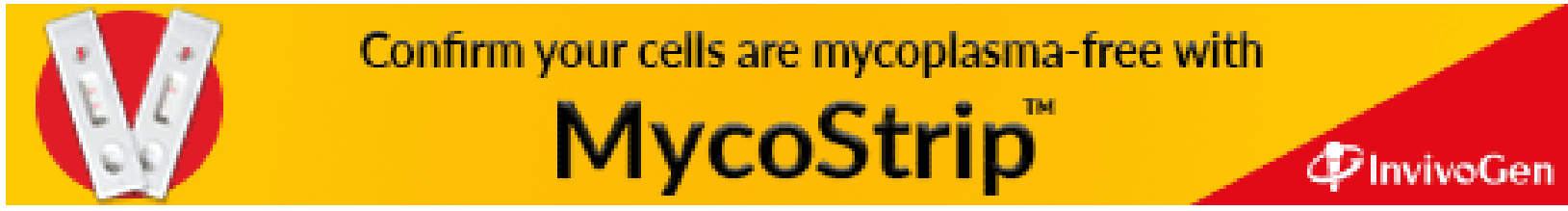

